\title{
RELATO DE EXPERIÊNCIA DO ESTÁGIO DE OBSERVAÇÃO EM UMA ESCOLA PARA PESSOAS COM DEFICIÊNCIA INTELECTUAL
}

\section{REPORT OF EXPERIENCE OF THE OBSERVATION INTERNSHIP IN A SCHOOL FOR PEOPLE WITH INTELLECTUAL DISABILITIES}

\section{Giovana Durigon Alves ${ }^{1}$; Luiza Constante Oliveira²; Luciane Najar Smeha ${ }^{3}$}

\section{RESUMO}

O presente trabalho tem por objetivo geral dissertar sobre a prática de estágio básico I, realizada em uma escola para pessoas com desenvolvimento atípico. Como também analisar de forma específica as relações interpessoais no ambiente escolar e compreender como ocorre o processo de aprendizagem na escola. $O$ estudo trata-se de uma análise documental, que caracteriza-se por identificar as informações contidas em documentos que não passaram por tratamento prévio (JUNIOR et al,. 2021). A análise dos dados coletados foi feita com base no método de análise de Bardin (2016), ou seja, pré análise, exploração e tratamento dos dados. Concluiu-se com o estudo, que o conhecimento é a principal estratégia para desconstruir preconceitos e estereótipos criados socialmente, principalmente a respeito das pessoas com desenvolvimento atípico. Por isso, a elaboração de trabalhos, como este, que contribuam para a desconstrução dessas ideias equivocadas se faz necessária.

Palavras-chave: Aprendizagem; Desenvolvimento atípico; Educação; Psicologia.

Eixo Temático: Atenção Integral e Promoção à Saúde.

\footnotetext{
${ }^{1}$ Giovana Durigon Alves - Universidade Franciscana - giovana.durigon@ufn.edu.br

${ }^{2}$ Luiza Constante Oliveira - Universidade Franciscana - luiza.constante@ufn.edu.br

${ }^{3}$ Luciane Najar Smeha - Docente na Universidade Franciscana - lucianes@ufn.edu.br
} 


\section{INTRODUÇÃO}

Os jovens com desenvolvimento atípico podem trazer em seu percurso várias marcas de situações de exclusão, o que os leva a buscar na escola um meio de dar continuidade ao seu desenvolvimento humano e social (SIEMS, 2012). Diante disso, fica evidente que a educação é uma das principais maneiras de inclusão e de crescimento pessoal. Assim, a escola além de proporcionar o contato com o meio social, ainda proporciona uma grande carga de ensinamentos que possibilitam o desenvolvimento desses sujeitos.

Segundo Arruda e Castanho (2014), é fundamental que a sociedade seja reformulada no modo de pensar as diferenças, para que, dessa forma, todos possam circular por ela sem nenhum preconceito. Além disso, a escola precisa repensar suas metodologias e seus currículos, de modo a alcançar todas as pessoas, incluindo as pessoas com deficiência. Da mesma forma, os autores afirmam que precisa-se desconstruir os estereótipos criados por trás da palavra "deficiência", para entender que existem inúmeros tipos de diagnósticos e que nenhum deles exclui a subjetividade do indivíduo. Assim, não se pode generalizar pessoas com desenvolvimento atípico, pois cada uma vai se expressar de uma forma singular, de acordo com suas vivências e sua personalidade.

Quando se fala em inclusão escolar de alunos com deficiência intelectual, é necessário citar o ganho de conhecimento, neste contexto, a percepção sobre as relações obtidas em sala de aula tem grande importância. É na forma como o educador interage com os alunos e tenta entender de que maneira eles estão construindo seu conhecimento, que ele consegue intervir nas situações de aprendizagem, tornando-se também aprendiz desse processo. Desta forma, o professor aprende com 0 aluno, e percebe que o educando com deficiência intelectual tem sua maneira única de construir o seu saber (VIEIRA, 2017).

Portanto, torna-se indispensável uma educação de qualidade, que abranja todas as pessoas, independentemente de suas deficiências. Sendo assim, as 
práticas educativas precisam se adequar às necessidades de cada aluno, levando em consideração suas dificuldades e facilidades. Porém, vale salientar, que a deficiência intelectual não será totalmente revertida, mas a educação é um processo-chave para a máxima formação humana e social (SANTOS, 2012).

Esse relato refere-se à prática de estágio básico $\mathrm{I}$, condizente ao segundo semestre de 2019, da Universidade Franciscana (UFN), o qual tem como método a observação participante. O mesmo ocorreu em uma escola voltada para o atendimento especializado de pessoas com desenvolvimento atípico, principalmente deficiência intelectual, em uma cidade do interior do Rio Grande do Sul. A escola é responsável pelo ensino de 218 alunos, onde trabalham 11 funcionários. As turmas são separadas a partir de atividades criativas e os alunos são divididos por níveis de aprendizagem. Deste modo, os alunos dividem-se entre as turmas de alfabetização, a sala de convivência e a sala de artesanato. Assim, a escola visa o desenvolvimento e a convivência dos alunos com outras pessoas e o contato com os meios sociais e culturais.

O presente trabalho tem por objetivo geral dissertar sobre a prática de estágio básico I, realizada em uma escola para pessoas com desenvolvimento atípico. Como também analisar de forma específica as relações interpessoais no ambiente escolar e compreender como ocorre o processo de aprendizagem na escola. Além disso, esse estudo pretende desconstruir alguns estereótipos e preconceitos criados socialmente sobre as pessoas com deficiência. Desta forma, destaca-se a importância da prática de estágio voltada para o desenvolvimento de pessoas com deficiência intelectual, pois as mesmas necessitam de um olhar de profissionais que busquem estratégias positivas frente às suas dificuldades e limitações.

\section{METODOLOGIA}

O presente trabalho trata-se de uma análise documental, que caracteriza-se por identificar as informações contidas em documentos destinados a estudos, os quais não passaram por tratamento prévio. Desse modo, os pesquisadores devem 
realizar uma análise e verificar se o documento é necessário e condiz com os objetivos esperados para a pesquisa (JUNIOR et al,. 2021). A pesquisa qualitativa realizou no período de agosto a dezembro de 2019, nas bases de dados Scientific Electronic Library Online (Scielo) e Periódicos Eletrônicos em Psicologia (Pepsic), periódicos de universidades brasileiras, revistas científicas, anais de eventos e livros.

A análise dos dados coletados foi feita com base no método de análise de Bardin (2016), o qual é dividido em três etapas principais, que são: A pré-análise, a exploração do material e o tratamento dos resultados. A pré-análise busca definir os objetivos e hipóteses da pesquisa, além de escolher quais materiais serão utilizados, a partir de uma leitura prévia. A exploração do material é a fase em que se analisa todas as obras escolhidas de forma mais aprofundada, com base nos objetivos estabelecidos na pré-análise. A última etapa, chamada de tratamento dos resultados, é quando o pesquisador interpreta todos os dados que ele coletou e consegue estruturar a sua pesquisa.

Esse relato é resultado das práticas de estágio básico I realizadas pela Universidade Franciscana, o qual é voltado para o desenvolvimento da técnica chamada de observação participante. Conforme May (2004), esse método de pesquisa vai muito além de uma simples observação, requer um entrosamento entre os observados e o observador. Assim, segundo Gil (2018), essa técnica facilita a inserção e compreensão sobre o meio em questão. Deste modo, a observação participante foi uma grande aliada durante o estágio, pois com ela foi possível relacionar a teoria com a prática, assim como, também possibilitou um olhar mais amplo sobre o ambiente, de modo a facilitar a aprendizagem e contribuir com a devolução.

A observação ocorreu em uma escola do interior do Rio Grande do Sul, a qual se dedica a atender adolescentes e adultos com desenvolvimento atípico, principalmente com deficiência intelectual. A escola é um centro de convivência filantrópico que oferece aulas de artesanato e alfabetização para os alunos, além de 
atendimentos psicológicos, serviços de fisioterapia, fonoaudiologia e terapia ocupacional. A instituição funciona em turno integral todos os dias da semana, mas cada aluno frequenta apenas um turno de acordo com seus horários e necessidades, e pode escolher quais dias irá comparecer.

As observações ocorreram uma vez por semana, com duração de uma hora meia (1h30) cada, aproximadamente, ao longo dos meses de setembro a novembro de 2019 e totalizaram cerca de 20 horas práticas ao final. Além disso, toda semana também eram feitas supervisões para discussões de casos e compartilhamento de experiências com a supervisora, na qual eram entregues relatórios semanais com os principais pontos observados ao longo da prática. No final do estágio foi elaborado um relatório final com todas as informações coletadas ao longo do semestre, além de uma devolução sobre o que a escola poderia fazer para melhor atender seus alunos.

Para sintetizar as informações coletadas durante as práticas de estágio e os materiais encontrados na literatura, foram criadas duas categorias, após a análise, nas quais foram enfocadas as relações interpessoais observadas na escola e o processo de aprendizagem dos alunos. Assim, nos resultados e discussões ficou estabelecidos os seguintes subtítulos: "Relações Interpessoais de pessoas com deficiência Intelectual" e "O potencial de aprendizagem".

\section{RESULTADOS E DISCUSSÕES}

\subsection{Relações Interpessoais de pessoas com deficiência Intelectual}

A questão das relações interpessoais foi algo bastante presente nas observações, durante o período de estágio. Assim, pode-se considerar que elas são a base da vida, pois para viver em sociedade é preciso saber conviver com o outro. Por isso, é necessário saber a importância das relações e interações sociais, sendo que esses fatores têm muita relevância quando o assunto é saúde mental (CARDOZO; SOARES, 2011). Neste sentido, as pessoas com deficiência intelectual, assim como todas as outras, precisam ser instigadas a terem relacionamentos 
interpessoais saudáveis para o seu desenvolvimento social e sua melhor qualidade de vida.

As pessoas com deficiência intelectual têm emoções como qualquer outro sujeito, porém, essas emoções muitas vezes não são consideradas. Assim, a sociedade os rotula como incapazes de sentir qualquer emoção, e quando as emoções são consideradas, elas são vistas como parte da deficiência (GAMEIRO et al., 2017). Deste modo, é possível salientar o preconceito decorrido da rotulação criada pela sociedade, o que traz a ideia de que pessoas com desenvolvimento atípico não possuem a capacidade de obter relacionamentos com outras pessoas.

É relevante salientar que, durante as observações do estágio, foi possível notar esse olhar preconceituoso de muitas pessoas para os indivíduos com desenvolvimento atípico. Um exemplo deste fato se deu em um passeio com os alunos da escola, onde eles foram a um shopping da cidade para olhar a decoração de natal. Enquanto eles caminhavam, o olhar que os alunos recebiam das pessoas era um olhar curioso e de desconforto, como se ali não estivessem seres humanos, mas uma espécie desconhecida. Este fato, evidencia o preconceito ainda sofrido pelas pessoas com deficiência.

O vínculo saudável das pessoas com deficiência intelectual e seus pais, ou responsáveis, é de extrema importância, pois pode ocasionar mais sentimentos de segurança nos relacionamentos interpessoais e melhora nos comportamentos sociais, além de que promove a autonomia e a qualidade de vida do sujeito (CARDOZO; SOARES, 2011). Sendo assim, uma questão complexa que pode ser abordada, é o fato de que muitas famílias não permitem a autonomia da pessoa com deficiência intelectual leve, a qual quer e pode trabalhar para ter sua independência financeira. Isso acontece, muitas vezes, porque os filhos com deficiência ganham um auxílio do governo e a família não quer perder essa renda extra. Assim, pessoas com desenvolvimento atípico, frequentemente, são impedidas de fazerem suas próprias escolhas e acabam perdendo sua autonomia, o que pode consequentemente acarretar em depressão ou até mesmo em transtornos mentais. 
Outro fator importante, é a presença dos grupos na vida de pessoas com deficiência intelectual. Deste modo, a possibilidade de inserção em um grupo deve ser oferecida, pois o contexto grupal abre várias oportunidades de desenvolvimento pessoal, além de proporcionar o relacionamento com sujeitos diferentes, o que possibilita muitos ganhos. O grupo possibilita que as pessoas tenham a oportunidade de compartilhar suas ideias e suas habilidades, permitindo um espaço para falar sobre diversos assuntos, como a sexualidade, por exemplo, a qual não é muito abordada com pessoas com deficiência intelectual. Ademais, ele também tem o papel de ajudar esses indivíduos a lidarem com frustrações que podem surgir ao longo da vida ( GAMEIRO et al. 2017).

Um exemplo de um grupo que tem muita importância para o desenvolvimento são as turmas formadas na escola onde ocorreu o estágio, pois os alunos têm a oportunidade de conviver com pessoas diferentes. Além de participar de oficinas que possibilitam a interação, como grupos de convivência, artesanato, dança, educação física e música. Desta forma, os alunos sentem-se mais confiantes para tomar uma posição frente às situações atípicas, pois eles são retirados da sua zona de conforto e postos em lugares em que devem tomar decisões e interagir com outras pessoas. Assim, estes fatores contribuem grandemente para a independência de pessoas com desenvolvimento atípico, principalmente com deficiência intelectual.

\subsection{0 potencial de aprendizagem}

A escola é uma grande aliada no desenvolvimento das pessoas com deficiência Intelectual, desse modo, tanto a qualidade de ensino dos professores, quanto a estrutura escolar oferecida para pessoas com deficiência intelectual são de extrema importância para o processo de aprendizagem. Durante as observações, ficou evidente o envolvimento dos professores com os alunos e o quanto a atenção oferecida a eles é fundamental, principalmente pela confiança e o carinho que os alunos destinavam aos professores. 
Contudo, a escola é a principal responsável pela educação de pessoas com deficiência intelectual, porém, o ensino oferecido aos alunos ainda está muito focado nas dificuldades e pouco nas possibilidades de aprendizagem (GOMES; SALVADORI; LEITE, 2019). Entretanto, na escola onde ocorreu a prática, os alunos são divididos nas turmas conforme suas habilidades, de modo, a facilitar o desenvolvimento de aprendizagem, pois se a pessoa com deficiência intelectual tiver oportunidades de fazer o que gosta e tem facilidade para fazer, ela irá desempenhar o seu papel com maior qualidade e se sentirá útil no processo.

O educador que trabalhar com alunos portadores de deficiência intelectual, não precisará necessariamente ser especialista em ensino de pessoas com deficiência intelectual, por não ser exigida uma especialização ou habilidade técnica, sendo suficiente a formação pedagógica do professor. Neste sentido, será importante para o desenvolvimento da aprendizagem a atualização do professor, seguindo cada aluno e suas necessidades individuais, visto que, os educandos com deficiência intelectual tem capacidade de aprendizagem, assim como os alunos com desenvolvimento intelectual normal (SANTOS, 2012).

Neste viés, na escola onde ocorreu a prática de estágio, as professoras não têm especialização em ensino de pessoas com deficiência intelectual, portanto, elas usam métodos de ensino que embasam as habilidades de cada aluno, facilitando o processo de aprendizagem. Assim, com a divisão das turmas por níveis de aprendizagem, os alunos conseguem acompanhar o que está sendo proposto em sala de aula e ainda os que apresentam um melhor desempenho ajudam os colegas que têm dificuldade durante as atividades, desta forma, todos aprendem e trabalham as relações interpessoais.

A escola é um espaço onde os deficientes intelectuais podem ser eles mesmos, expondo suas habilidades, buscando desenvolvimento e muitas vezes buscando por atenção. Segundo as observações, os educandos demonstram carência no dia a dia na escola, eles procuram sempre abraçar e sentirem-se seguros, deste modo, eles transferem muito carinho para os funcionários e para os 
estagiários. Assim, como afirma Cardozo e Soares (2011), as habilidades das pessoas com deficiência intelectual são de extrema importância para a Avaliação dessas pessoas, pois, por elas é possível identificar dificuldades como na comunicação não verbal, nas habilidades assertivas de lidar com críticas e de discordar e recusar algo, assim, os profissionais podem intervir e ajudar os alunos nas suas demandas.

Entretanto, os pais têm cerne importância no desenvolvimento dos filhos com deficiência intelectual, eles devem estar presentes em suas vidas, pois situações em que envolvam interações de pais e filhos podem trazer sentimento de segurança e confiança, o reforço familiar ocasiona autoestima em pessoas com deficiência intelectual e consequentemente isso reflete na interação da pessoa em outros contextos que ele convive. Se a família for estável e carinhosa, a probabilidade de o deficiente intelectual ser uma pessoa mais tranquila pode ser maior, assim como, se a família for agitada e violenta o deficiente poderá agir com agitação e violência. Assim, fica evidente a importância da família na vida desses sujeitos, de modo, que a família é a base e o primeiro contato com um grupo, é na família e com a família que as pessoas aprendem a conviver em sociedade.

Neste viés, abordando as observações realizadas em estágio, a inserção de estagiários na escola teve grande contribuição na aprendizagem e no desempenho dos alunos, pois eram poucos professores para muitos educandos, e mesmo com a atenção e o carinho no ensino as professoras não conseguiam abranger as necessidades de todos, assim, eles recorriam aos estagiários que estavam nas salas. Deste modo, esta troca entre alunos e estagiários possibilitou uma maior compreensão sobre a deficiência Intelectual de cada um, por parte dos estagiários e uma confiança e a convivência com pessoas diferentes, por parte dos alunos.

\section{CONCLUSÃO}

Esse trabalho se propôs a descrever as experiências adquiridas durante 0 estágio básico I, realizadas em uma escola especializada para pessoas com 
desenvolvimento atípico, principalmente com deficiência intelectual. Assim, ao longo da discussão foi dado um destaque para as relações interpessoais observadas no ambiente escolar e para os processos de aprendizagem que ocorrem na escola. Além disso, também foi possível refletir sobre o preconceito que ainda existe com as pessoas que possuem um desenvolvimento atípico, o qual ficou evidente no decorrer das observações.

Durante o período de estágio, pode-se perceber que os relacionamentos são a base da vida em sociedade, e para as pessoas com deficiência intelectual não é diferente. Neste sentido, é necessário que os indivíduos com desenvolvimento atípico sejam instigados a desenvolver suas habilidades sociais e sua autonomia, por isso, uma compreensão deste fato por parte da família é fundamental. Ademais, a criação de grupos de convivência para os indivíduos com deficiência intelectual se mostrou bastante necessária, pois eles permitem uma interação entre pessoas diferentes e possibilitam um espaço para troca de conhecimentos.

Com este estudo, foi possível notar que a escola pode ser uma aliada no desenvolvimento das pessoas com deficiência intelectual, por isso, um ensino de qualidade e uma boa estrutura escolar são fundamentais. Além disso, é necessário que os professores busquem estar sempre atualizados, para conseguirem dar conta das demandas e se adaptarem ao modo de aprender de cada estudante. Porém, é evidente que a educação oferecida para esse público ainda enfoca bastante nas dificuldades e pouco nas potencialidades dos alunos, o que dificulta o processo de aprendizagem.

O conhecimento é a principal estratégia para desconstruir preconceitos e estereótipos criados socialmente, principalmente a respeito das pessoas com desenvolvimento atípico. Por isso, a elaboração de trabalhos, como este, que contribuam para a desconstrução dessas ideias equivocadas se faz bastante necessária. Assim, pode-se concluir que a informação pode ser uma aliada nesse processo, o que irá facilitar o desenvolvimento social e a autonomia das pessoas 
EDUCAÇÃO, SAÚDE

ETECNOLOGIA

26 A 28 DE OUTUBRO DE 2021

com deficiência, e consequentemente trará mais qualidade de vida para esses indivíduos.

\section{REFERÊNCIAS}

ARRUDA, I. R.; CASTANHO, M. I. S. Educação de jovens e adultos deficientes mentais: reflexões sobre a permanência na escola especial. Construção Psicopedagógica, São Paulo, v. 22, n. 23, p. 59-71, 2014. Disponível em: http://pepsic.bvsalud.org/scielo.php?script=sci_arttext\&pid=S1415-69542014000100 005. Acesso em: 6 set. 2019.

BARDIN, L. Análise de conteúdo. São Paulo: Edições 70, 2016.

CARDOZO, A.; SOARES, A. B. Habilidades Sociais e o Envolvimento entre Pais e Filhos com Deficiência Intelectual. Psicologia: Ciência e Profissão. v. 1, p. 110-119, 2011. Disponível em: https://www.scielo.br/j/pcp/a/PWCNQGSQx7LTVCPj8HmrFgS/abstract/?lang=pt. Acesso em: 9 nov. 2019.

GAMEIRO, A. C. P.; MENEZES, C. C.; SOUZA, C. R.; FERREIRA, S. L. Expressividade Emocional e Deficiência Mental: Uma Relação a Ser Considerada. IV Congresso Brasileiro Multidisciplinar de Educação Especial. Londrina, 29 a 31 de outubro de 2007.2 Disponível em: http://www.uel.br/eventos/congressomultidisciplinar/pages/arquivos/anais/2007/026.p df. Acesso em: 8 dez. 2019.

GIL, A. C. Métodos e técnicas de pesquisa social. 6 ed. São Paulo: Atlas, 2008.

GOMES, I. A. S; SALVADORI, J. C.; LEITE, K. C. N. Grupo Terapêutico de Atividades Lúdico Desportivas Para Alunos Com Deficiência Intelectual: Relato de Experiência. In: MACHADO, D. H. A.; CAZINI, J. (Org.) Inclusão e Educação, v. 3, Ponta Grossa: Atena Editora, 2019. Disponível em: 
https://www.atenaeditora.com.br/wp-content/uploads/2019/01/Inclus\%C3\%A3o-e-Ed uca\%C3\%A7\%C3\%A3o-3-1.pdf. Acesso em: 7 dez. 2019.

JUNIOR, E. B. L.; OLIVEIRA, G. S.; SANTOS, A. C. O.; SCHNEKENBERG, G. F. Análise documental como percurso metodológico na pesquisa qualitativa. Cadernos da Fucamp, v. 20, n. 44, p.36-51. 2021. Disponível em: https://www.fucamp.edu.br/editora/index.php/cadernos/article/view/2356/1451. Acesso em: 29 set. 2021.

MAY, T. Observação participante: perspectivas e práticas. Pesquisa Social: questões, métodos e processos, 3 ed. Porto Alegre: Artmed, 2004. Disponível em: http://www2.fct.unesp.br/docentes/geo/necio_turra/PPGG\%20-\%20PESQUISA\%20Q UALI\%20PARA\%20GEOGRAFIA/Pesquisa\%20Social\%20Quest\%F5es, \%20m\%E9to dos\%20e\%20processos.pdf. Acesso em: 6 set. 2019.

SANTOS, D. C. O. Potenciais dificuldades e facilidades na educação de alunos com deficiência intelectual. Educação e Pesquisa, São Paulo, v. 38, n. 4, p. 935-948. Out./dez. 2012. http://www.scielo.br/scielo.php?pid=S1517-97022012000400010\&script=sci_abstract \&tIng=pt. Acesso em: 6 set. 2019.

SIEMS, M. E. R. Educação de jovens e adultos com deficiência: saberes e caminhos em construção. Educ. foco, Juiz de Fora, fev. 2012. Disponível em: http://www.ufff.br/revistaedufoco/files/2012/08/Texton-031.pdf. Acesso em: 6 set. 2019.

VIEIRA, S. C. A. Deficiência intelectual: construção do conhecimento e o atendimento educacional especializado. $1^{\text {o }}$ Seminário Luso-Brasileiro de Educação Inclusiva: O ensino e a aprendizagem em discussão, mai. 2017. Disponível em: http://editora.pucrs.br/anais/i-seminario-luso-brasileiro-de-educacao-inclusiva/assets/ artigos/eixo-5/completo-8.pdf. Acesso em: 6 set. 2019. 